\title{
Ovulation timing and conception risk after automated activity monitoring in lactating dairy cows ${ }^{1}$
}

\author{
J. S. Stevenson, ${ }^{* 2}$ S. L. Hill, ${ }^{*}$ R. L. Nebel, $†$ and J. M. DeJarnette† \\ *Department of Animal Sciences and Industry, Kansas State University, Manhattan 66506-0201 \\ †Select Sires Inc., Plain City, OH 43064-0143
}

\begin{abstract}
Using 1 market-available activity monitor, 3 experiments were conducted in dairy cows to determine timing of ovulation, compare within-herd conception risk of cows inseminated based on activity monitors versus timed artificial insemination (AI), and determine conception risk of cows inseminated at various intervals after achieving an activity threshold. In experiment 1, ovaries were scanned every $3 \mathrm{~h}$ by transrectal ultrasonography to determine the time of ovulation beginning $14 \pm 0.5 \mathrm{~h}$ after the achieved activity threshold $(\mathrm{n}=$ $132)$ or first standing event $(\mathrm{n}=59)$, or both $(\mathrm{n}=59)$. Progesterone at the first ovarian scan $(0.1 \pm 0.01 \mathrm{ng} /$ $\mathrm{mL}$ ) and ovarian structures [1 or 2 preovulatory-sized follicles $(16.5 \pm 0.2 \mathrm{~mm})$ ] confirmed that $88.6 \%$ of cows identified by activity were in estrus. The remaining 15 cows $(11.4 \%)$ with a corpus luteum and elevated progesterone concentration $(5.3 \pm 0.5 \mathrm{ng} / \mathrm{mL})$ were classified as false positives. The average interval from first standing event to ovulation $(\mathrm{n}=59)$ differed slightly from the interval after the achieved threshold (26.4 \pm 0.7 vs. $24.6 \pm 0.7 \mathrm{~h}$, respectively). In 97 cows fitted with activity monitors, that interval was $25.7 \pm 0.4 \mathrm{~h}$. In experiment 2, the conception risk in 394 cows in 1 herd fitted with activity monitors was compared with that of 413 cows submitted to a timed AI program through 3 AI services. Days to first AI were reduced in cows fitted with activity monitors, and conception risk after activity threshold was less than that for timed AI at first service because of differing days in milk at first AI. Both median and mean days to pregnancy, however, were reduced in activity-group cows by 10 and $24 \mathrm{~d}$, respectively, compared with timed AI cows. In experiment 3, 4,019 cows in 19 herds were inseminated after achieving the activity threshold. Conception risk was determined for cows inseminated at various intervals after the achieved activity threshold. A curvilinear

\footnotetext{
Received December 23, 2013.

Accepted April 4, 2014.

${ }^{1}$ Contribution number 14-197-J from the Kansas Agricultural

${ }^{2}$ Corresponding author: jss@k-state.edu
} Experiment Station, Manhattan.
\end{abstract}

conception risk curve peaked at $47.9 \%$ for primiparous cows inseminated between 13 and $16 \mathrm{~h}$, whereas conception risk in multiparous cows was steady at $34 \%$ through $12 \mathrm{~h}$ and decreased thereafter. These experiments demonstrate that time of ovulation after activity threshold closely resembles the time of ovulation after first standing estrus. Time of insemination up to $12 \mathrm{~h}$ after the activity threshold produced similar conception risks for multiparous cows, whereas intervals shorter than 13 and greater than $16 \mathrm{~h}$ in primiparous cows seemed to compromise their conception risk. Although conception risk may not be improved at individual inseminations after achieving an activity threshold, the rate of achieving pregnancy is hastened. Activity monitors can accurately predict ovulation and time of AI.

Key words: activity monitor, conception risk, insemination time, ovulation time

\section{INTRODUCTION}

Several significant physiological changes occur in cows during the periestrual period (Lewis and Newman, 1984; Roelofs et al., 2010; Saint-Dizier and Chastant-Maillard, 2012), thus enabling detection of estrual behaviors and other correlated traits. Some of these changes include physical activity, vaginal cytology and $\mathrm{pH}$, electrical resistance of vaginal mucus and genital tissues, body temperature, pulse and heart rates, blood flow, pheromones or odors, blood metabolites and hormones, milk yield, and DMI.

Accurate prediction of ovulation is the goal of a successful estrus-detection program. Improvement in AI service rate required for a $100 \%$ estrus-detection-based AI program to have the same economic net present value as a superior $100 \%$ timed AI program was $12 \%$ (Giordano et al., 2011). Furthermore, adding detection of estrus to a $100 \%$ timed AI program was beneficial only for a timed AI program with the lowest conception risk. Thus, reducing costs associated with timed AI programs by improving efficiency and accuracy of detected estrus (increased AI service rate) should reduce the cost per pregnancy in most herds because interinsemination intervals are reduced from $40-50 \mathrm{~d}$ to 
20-24 d when nonpregnant cows are identified at the first possible post-AI estrus.

Several technologies can serve as ovulation prediction aids, including heat mount-detection patches and pressure-sensitive rump-mounted radiotelemetric devices that identify cows that have received mounts from herd mates (Firk et al., 2002). These technologies assess mounts received by the targeted cow but require visual inspection of the cow to determine if other signs of estrus validate the trigger. Monitoring activity has formed the basis for many pedometer or neck-mounted monitoring systems marketed to the dairy industry because increased activity (e.g., motion, movement, and walking) is a trait correlated with estrus, with activity increasing up to $400 \%$ in $93 \%$ of estrous periods (Kiddy, 1977). One challenge limiting any system is the lesser activity associated with estrus for cows maintained in tie-stalls compared with freestalls (Roth, 1987), or for cows in total confinement on concrete compared with dirt lots (Vailes and Britt, 1990).

Accelerometers now used in activity monitors were first developed for the military, aerospace, and automotive industries. They have the capacity to detect motion in all 3 spatial planes. Increased walking activity that is associated with estrus (Roelofs et al., 2010) led to the development of pedometry as a means of detecting estrus as early as the 1970s. Pedometers affixed to the leg or neck quantified cow movement or counted the number of steps taken by the cow. Increase in physical activity of the cow provided 70 to $80 \%$ accuracy of detected estrus (Roelofs et al., 2010). Cows housed in freestalls were approximately 2.75 times more active during estrus than when not in estrus; furthermore, relatively little within-cow variation in activity occurred from day to day when cows were not in estrus. Therefore, activity monitors may be acceptable predictors of sexual and other behaviors associated with estrus.

Relationships between increased activity, time of ovulation, and fertility have been investigated with the help of activity monitors (López-Gatius et al., 2005; Roelofs et al., 2005; Hockey et al., 2010a). In general, ovulation takes place an average of 29 to $33 \mathrm{~h}$ after the onset of increased activity and 17 to $19 \mathrm{~h}$ after the end of increased activity in lactating Holstein cows (Roelofs et al., 2005; Hockey et al., 2010a). In previous studies (López-Gatius et al., 2005; Roelofs et al., 2005; Hockey et al., 2010a), predicted time of ovulation was in reasonable agreement with that in the study of Walker et al. (1996), in which ovulation occurred at $27.6 \pm 5.4 \mathrm{~h}$ (mean $\pm \mathrm{SD}$ ) after the onset of estrus. It seems likely that increased activity was largely correlated with the onset of standing estrus in studies where simultaneous measurements were made.
One of the limitations of activity monitors is knowing when ovulation occurs relative to increased activity. Large-scale studies determining when ovulation occurs, proper timing of ovulation, and subsequent conception risk, and comparisons of this technology with proven timed AI programs are not available. Using a marketavailable automated activity monitor [Select Detect (SDet) accelerometer; Select Sires Inc., Plain City, $\mathrm{OH}]$, our objectives were 3-fold: to (1) determine the time of ovulation in lactating dairy cows after achieving an activity threshold, (2) compare within-herd reproductive traits in cows submitted to AI based on either activity monitors or a strict timed AI program, and (3) determine actual conception risk of cows inseminated at various intervals after achieving activity thresholds in multiple herds.

\section{MATERIALS AND METHODS}

\section{Experiment 1}

Experimental Cows. This experiment was approved by the Kansas State University Institutional Animal Care and Use Committee (Manhattan). Lactating Holstein cows were housed at the Kansas State University Dairy Teaching and Research Center in covered freestalls and fed twice or 3 times (summer) daily a TMR calculated to meet nutrient requirements for lactating dairy cows producing $50 \mathrm{~kg}$ of $3.5 \%$ milk (NRC, 2001). The diet consisted of alfalfa hay, corn silage, soybean meal, whole cotton seed, corn or milo grain, corn-gluten feed, vitamins, and minerals.

To determine when ovulation occurred relative to achieving an activity threshold (identified by the activity software), cows were enrolled in a study beginning at 50 DIM. Cows were administered i.m. either $25 \mathrm{mg}$ of $\mathrm{PGF}_{2 \alpha}$ (Lutalyse; Pfizer Animal Health, New York, NY) or $100 \mu \mathrm{g}$ of GnRH (Factrel; Pfizer Animal Health) that preceded the $\mathrm{PGF}_{2 \alpha}$ injection by $7 \mathrm{~d}$ to induce estrus. Observations of $\mathrm{PGF}_{2 \alpha}$-induced or spontaneously increased activity were identified before or after first AI. Primiparous and multiparous cows were fitted with neck-collar-mounted automated activity monitors (SDet; Select Sires Inc.). In addition, 66 of the 132 cows also were fitted with rump-mounted, pressuresensitive transmitters [HeatWatch $(\mathbf{H W})$; Cow Chips LLC, Manalapan, NJ]. Combining technologies allowed comparisons of the onset of estrus (first mount received per HW) with onset of the achieved activity threshold as determined by the activity system. The threshold of physical activity detection was set at the factory at 290 and never changed during the entire experiment. Monitors use a microelectronic motion-sensing 
accelerometer that measures 3-dimensional movement in meters per second squared (quantified as counts in the software). Monitors uploaded information to a base station located in the holding pen. Cows were milked 3 times daily at 0700,1500 , and $2300 \mathrm{~h}$ and daily milk yield was recorded.

Ovulation Detection. Once a cow was detected in estrus (at least 1 standing event) or the hourly activity count reached the threshold (based on SDet software), or both, transrectal ovarian ultrasonography $(7.5-\mathrm{MHz}$ linear-array transducer, Aloka 500V; Corometrics Medical Systems Inc., Wallingford, CT) was initiated beginning at $14.5 \pm 0.5 \mathrm{~h}$ and continued every $3 \mathrm{~h}$ until the ovulatory follicle(s) disappeared or until $36 \mathrm{~h}$.

At the initial scan, all follicular structures were mapped and sized with electronic calipers. The largest 2 follicles were monitored until either or both disappeared. When the follicle(s) disappeared upon ovarian scan, ovulation was assumed to have occurred at the midpoint between the last 2 scans. A BCS (0.25-point increments; $1=$ thin and $5=$ fat; Ferguson et al., 1994) was assigned and a blood sample was collected via tail vessel puncture at the first ovarian scan to measure concentrations of progesterone. Low progesterone $(<1$ $\mathrm{ng} / \mathrm{mL}$ ) plus the presence of at least 1 preovulatorysized follicle $(>12 \mathrm{~mm})$ and absence of a corpus luteum were evidence of true estrus. Concentrations of progesterone in blood serum were measured in all samples by direct quantitative (nonextracted) RIA using Coat-ACount progesterone kits (catalog no. TKPG; Siemens Medical Solutions Diagnostics Inc., Los Angeles, CA) and validated for bovine serum (Stevenson et al., 2012).

Measurements. Several variables were recorded from the HW (time of initial and final standing event, number of standing events, and total standing time) and SDet software (time when activity first met threshold, end of threshold activity, and peak threshold activity). Intervals to ovulation were calculated from the onset and end of estrus or the onset, peak, and end of threshold activity as well as duration of estrus and total activity time above threshold.

Statistical Analyses. Contemporary comparisons of estrus and activity measures were made in 59 to 66 cows fitted with both devices (the number varied because of some missing information). Analysis of variance (PROC GLM; SAS Institute Inc., Cary, NC) was used to assess differences between devices for the duration of estrus or activity; intervals to ovulation after onset, peak, and end of estrus; or activity threshold. The final model (no interactions were detected; $P>$ 0.20 ) included fixed effects of device (HW vs. SDet), parity (primiparous vs. multiparous), BCS ( $\leq 2.5$ vs. $>2.5$ ), median daily milk yield on the day of detected estrus or activity ( $\leq 45$ vs. $>45 \mathrm{~kg}$ ), and administra- tion of $\mathrm{PGF}_{2 \alpha}$ before detection (0 vs. 1 ). Where device measures were unique (number of standing events, total standing time, and peak threshold activity), device was excluded from the model.

A general linear model was applied to determine relationships between the first standing event of estrus to ovulation and first achieved and peak threshold activity to ovulation, last standing event of estrus and end of threshold activity to ovulation, and duration of estrus and duration of threshold activity. Proportions of cows ovulating at 5-h intervals after the onset of estrus or activity $(<20,20$ to $24.9,25$ to 29.9 , and $\geq 30 \mathrm{~h})$ were compared between devices by chi-squared test, and differences were detected by the Cochran-Mantel-Haenszel general association statistic in PROC FREQ of SAS. In a similar analysis, circadian onset of standing estrus or activity threshold was assessed (0000 to 0559,0600 to 1159,1200 to 1759 , and 1800 to 2359 h) by chi-squared test. Simple correlations among variables were determined by PROC CORR in SAS.

\section{Experiment 2}

Experimental Cows. The objective of a second experiment was to assess reproductive performance of lactating dairy cows in 1 herd in which comparisons were made between 2 AI management systems. Cows were enrolled either in a strict timed AI program for the first 3 services after calving with a later voluntary waiting period (70 DIM) or in an activity system with a shorter waiting period (50 DIM). The experiment ended for individual cows when they received their third AI after calving. Cows were enrolled during an entire year in a commercial 832-cow dairy located in central Pennsylvania.

Cows $(\mathrm{n}=413)$ enrolled in a Presynch-Ovsynch-56 timed AI program received $\mathrm{PGF}_{2 \alpha}$ at 36 and $50 \mathrm{DIM}$ and GnRH 11 d later (d 61). On d 68, cows received $\mathrm{PGF}_{2 \alpha}$ and the final $\mathrm{GnRH}$ injection $56 \mathrm{~h}$ later. Timed AI occurred 8 to $16 \mathrm{~h}$ after the last $\mathrm{GnRH}$ injection. A new cohort group of cows was initiated weekly. Nonpregnant timed-AI cows were resynchronized, receiving GnRH $7 \mathrm{~d}$ before pregnancy determination and $\mathrm{PGF}_{2 \alpha}$ at a nonpregnant diagnosis and then $\mathrm{GnRH} 56 \mathrm{~h}$ later with timed $\mathrm{AI}$ at 8 to $16 \mathrm{~h}$ after GnRH injection. When determined not pregnant after the third AI service, cows were fitted with an activity monitor.

Cows assigned to the activity group $(\mathrm{n}=394)$ were fitted with a neck-mounted accelerometer activity monitor (SDet; same system as described in experiment 1; the threshold activity was set at the factory at 290 and never changed) the first Monday after 40 DIM, and if not inseminated by $54 \mathrm{DIM}, \mathrm{PGF}_{2 \alpha}$ was administered. If not inseminated by 75 DIM, a progesterone-impregnat- 
ed intravaginal insert [controlled internal drug release (CIDR); Pfizer Animal Health) + Ovsynch-56 protocol was administered with timed AI 8 to $16 \mathrm{~h}$ after the last GnRH injection and between 85 and 91 DIM. If cows in the activity group were not pregnant after the third service, the resynchronization protocol used for timedAI cows was administered thereafter. The herdsman gave all injections to cows in the timed-AI system and performed all inseminations for cows in both systems, except on every other weekend. Pregnancy diagnoses were determined by uterine palpation 35 to $41 \mathrm{~d}$ after last AI.

Measurements. Estrus-detection and 21-d pregnancy rates were calculated by PCDART software (Dairy Records Management Systems, Raleigh, NC) as described in the DHI Glossary Fact Sheet (DRMS, 2013). Briefly, estrus-detection rate $=$ [number of services and heats reported in the test period for eligible cows/ (estrous cycle days in test period for eligible cows/21)] $\times 100$. The 21-d pregnancy rate uses an algorithm to determine eligible cows in 2 groups: those eligible for insemination and those eligible to be called pregnant. To be eligible, cows must have a known outcome, and must be eligible for at least $11 \mathrm{~d}$ of the 21-d interval. In the insemination group, the insemination rate is determined by those inseminated divided by number of eligible cows. In the pregnancy group, the pregnancy rate is determined by those that conceived divided by the number of eligible cows.

Statistical Analyses. Data available from this study included all on-farm DHIA records (PCDART; Dairy Record Management Systems) plus individual cow records containing calving date, date of AI services, parity, and conception outcomes. Days to first AI service were analyzed by ANOVA using a general linear model in SAS consisting of system (timed AI vs. activity monitor), parity (primiparous vs. multiparous), season of first AI (spring: March 21 through June 19; summer: June 20 through September 19; autumn: September 20 through December 19; and winter: December 20 through March 20), and interaction of system and parity.

Binomial conception risk at first AI was analyzed with PROC GLIMMIX in SAS by applying a logistical model consisting of system, parity, sire, season at first $\mathrm{AI}$, and interaction of system and parity.

Days to initiation of pregnancy were analyzed by the Cox proportional hazard model. The hazard of pregnancy estimated the relative rate of pregnancy achievement according to the explanatory variables used in the model. The time variable used in the model was the interval in days from between calving and pregnancy through 3 AI services or censored (sold, dead, or remained not pregnant at 188 DIM). Proportionality was assessed by evaluating the Kaplan-Meier curves. Median and mean days to pregnancy were obtained from PROC LIFETEST of SAS.

\section{Experiment 3}

Experimental Cows and Data. The objective of this experiment was to determine the effects of interval to AI on conception risk of dairy cows submitted to AI service based on achieving threshold activity using automated SDet activity monitors (same system as described in experiment 1). Experimental cows housed in freestalls in 19 Holstein herds, ranging in size from 115 to $1,065(322 \pm 144$; mean $\pm \mathrm{SD})$ cows per farm, were located in 8 states (PA, OH, MI, WI, IL, IA, MN, and UT). Stocking density was $<120 \%$ in all breeding group pens.

Farm personnel inseminated cows at random intervals after onset of threshold activity according to standard procedures, which in 15 herds was a once-daily AI program and the a.m.-p.m. rule in the remaining 4 herds, so AI was performed after morning and evening milkings. Data collected from the SDet software included cow identification; onset, peak, and end of threshold activity; and peak activity counts. Individual cow data (parity, calving and AI dates, service number, peak lactation daily milk yield, and pregnancy outcomes) were recorded in a spreadsheet and merged with activity data. Pregnancy diagnoses varied by herd and were determined by transrectal ultrasound or uterine palpation 30 to $40 \mathrm{~d}$ since last AI.

Statistical Analyses. Calculations were made from SDet software to produce the hour when activity first met the threshold, hour of peak of threshold activity, and hour at end of threshold activity. Intervals from onset of threshold activity to AI were calculated as well as duration of total threshold activity (duration of activity). A total of 4,125 activity periods were originally examined. Data from 106 cows were deleted because of lameness $(\mathrm{n}=35)$ and activity periods that exceeded $33 \mathrm{~h}(\mathrm{n}=71)$ because of suspected cystic ovarian structures. All binomial comparisons of conception risk included 4,019 activity periods. A model examining conception risk was constructed using logistic regression (PROC LOGISTIC in SAS), consisting of the random effect of farm and fixed effects of parity (primiparous vs. multiparous), service number $(1,2$, or $3+$ ), duration of activity above threshold ( $<10$ vs. $\geq 10$ h), peak threshold activity ( $\leq 150$ vs. $>150$ counts), interval to AI from achieved threshold $(<4,5$ to 8,9 to 12,13 to 16 , or $>17 \mathrm{~h}$ ), 2-way interactions of parity by service number, parity by interval to AI, service number by duration of activity, peak threshold activity by duration of activity above threshold, median DIM 
$(<106$ vs. $\geq 106$ d), median lactation daily peak milk yield $(<50$ vs. $\geq 50 \mathrm{~kg})$, and season nested within farm. The final model produced by backward stepwise selection of independent variables entered or retained in the model was based on a Wald statistic $(P<0.10)$. Measures of DIM, peak milk, and the 2-way interaction of peak threshold activity by duration of activity above the threshold were not retained in the final model used in PROC GLIMMIX in SAS to generate $F$-values and adjusted mean percentages.

Various factors suspected to affect duration and peak threshold activity included 3,400 observations because data were collected in only 14 of 19 herds during the entire year. Seasonal comparisons were made using data from 14 herds with activity periods during summer (July 1 through September 11) and the rest of the year (October 30 through June 30). A final general linear model (PROC GLM of SAS) was used to determine the effects of season (summer vs. rest of the year), farm (n $=14$ ), parity (primiparous vs. multiparous), median DIM ( $<102$ vs. $\geq 102$ d), median lactation daily peak milk yield ( $<49$ vs. $\geq 49 \mathrm{~kg}$ ), and parity by season on duration of activity and peak activity counts.

\section{RESULTS}

\section{Experiment 1}

Activity Measures. Of 132 cows enrolled, 117 $(88.6 \%)$ had concentrations of progesterone $<1 \mathrm{ng} /$ $\mathrm{mL}$ and 15 (11.4\%) had elevated concentrations of progesterone at the first ovarian scan (Table 1). Eleven of the 15 high-progesterone cows were identified by activity monitors (false positives). Of these 11 cows, 3 occurrences of 2 cows were detected at threshold levels together, and 1 occurrence of 5 cows was detected together within 1 to $5 \mathrm{~h}$ of each other. Of 117 lowprogesterone cows, $91.5 \%$ ovulated $(85.5 \%$ ovulated $<36 \mathrm{~h}$ after detection by the activity monitor). Of the total data collected with the activity monitor, 59 of 106 ovulating cows also had complete HW-transmitter data (Table 1).

A circadian distribution of the onset of standing estrus and onset of achieved activity threshold in the same 66 cows illustrates small differences when these activities were initiated (Figure 1). A tendency $(P=$ $0.10)$ occurred for more activity in cows to reach the threshold during the first quartile of the day (0000 to $0559 \mathrm{~h}$ ) compared with onset of the first standing estrus in the same cows.

Ovulation Measures. Actual deviations between onset of standing estrus and achieved activity threshold differed by $1.75 \pm 0.4 \mathrm{~h}$ (range of -9.8 to $9.4 \mathrm{~h}$; i.e., on average, the first standing event preceded achieved
Table 1. Characteristics of cows that were detected in estrus or that reached the activity threshold (experiment 1)

\begin{tabular}{lc}
\hline Item & $\%$ (no./total no.) \\
\hline Low progesterone $^{1}($ mean $=0.10 \pm 0.01 \mathrm{ng} / \mathrm{mL})$ & $88.6(117 / 132)$ \\
Ovulation $^{2}$ & $90.6(106 / 117)$ \\
Activity $^{3,4}$ & $91.5(97 / 106)$ \\
No ovulation $^{(>36 \mathrm{~h})}$ & $9.4(11 / 117)$ \\
High progesterone $^{1,5}($ mean $=5.25 \pm 0.55 \mathrm{ng} / \mathrm{mL})$ & $11.4(15 / 132)$ \\
\hline
\end{tabular}

${ }^{1}$ Concentration (mean $\pm \mathrm{SE}$ ) detected at $14 \pm 0.5 \mathrm{~h}$ after first detected activity threshold.

${ }^{2}$ Ovulation was determined by ovarian ultrasonography exams every 3 $\mathrm{h}$ after first detected activity threshold. Includes 9 cows that ovulated at unknown times before ovarian exams or after $36 \mathrm{~h}$.

${ }^{3}$ Includes 13 cows with known ovulation times that did not meet the threshold; but 11 of 13 were detected in standing estrus by HeatWatch (Cow Chips LLC, Manalapan, NJ).

${ }^{4}$ Only $59(55.7 \%)$ of total cows were fitted with HeatWatch transmitters.

${ }^{5}$ False positives. All cows had a functional corpus luteum. Eleven of 15 cows had achieved the activity threshold between 1 and $5 \mathrm{~h}$ of each other (3 occurrences of 2 cows and 1 occurrence of 5 cows active together).

activity threshold). No other differences in onset of activity or estrus occurred during the remainder of the day (Figure 1). Cows that stood to be mounted and then ovulated earlier rather than later after the first standing event were more $(P<0.001)$ likely to show standing behavior after the activity threshold was achieved $(\mathrm{r}=0.54)$. As interval from the first standing event to ovulation increased $(<20 \mathrm{~h}$ to $\geq 30 \mathrm{~h})$, the differential in time between the first standing event and activity threshold achievement increased from $-2.6 \pm$

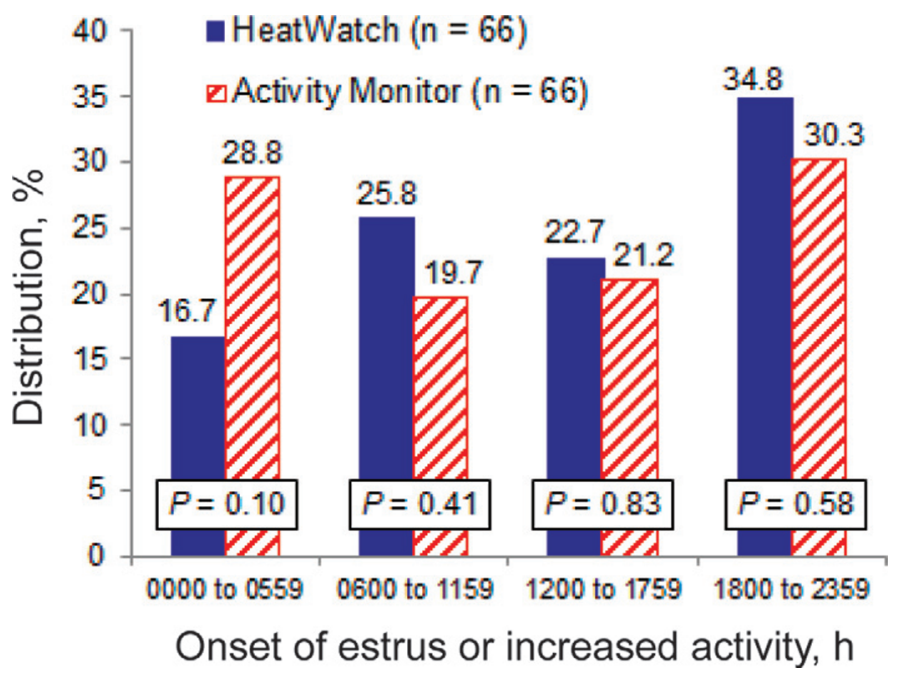

Figure 1. Circadian distribution of onset of standing estrus or achieved threshold activity of lactating dairy cows fitted with HeatWatch pressure-sensitive, rump-mounted, estrus-detection devices (Cow Chips LLC, Manalapan, NJ) and automated activity accelerometers (Select Detect; Select Sires Inc., Plain City, OH; experiment 1). Color version available in the online PDF. 
Table 2. Characteristics of estrus and ovulation relative to estrus activity determined by automated activity accelerometers (Select Detect; Select Sires Inc., Plain City, OH) or by standing to be mounted (experiment 1) 1 , 2

\begin{tabular}{|c|c|c|c|}
\hline \multirow[b]{2}{*}{ Item } & \multicolumn{2}{|c|}{ Detection device } & \multirow[b]{2}{*}{$P$-value } \\
\hline & HeatWatch ${ }^{3}$ & Activity monitor & \\
\hline \multicolumn{4}{|l|}{ Cows fitted with both devices } \\
\hline Duration of estrus or activity, ${ }^{4} \mathrm{~h}$ & $7.1 \pm 0.9(44)$ & $11.4 \pm 0.8(44)$ & $<0.001$ \\
\hline Standing events, no. & $5.9 \pm 1.2(59)$ & - & - \\
\hline Total duration of standing events, s & $11.7 \pm 2.7(59)$ & - & - \\
\hline Onset of estrus or activity ${ }^{4}$ to ovulation, $\mathrm{h}$ & $26.4 \pm 0.7(59)$ & $24.6 \pm 0.7(59)$ & 0.027 \\
\hline End of estrus or activity ${ }^{4}$ to ovulation, h & $21.0 \pm 0.9(54)$ & $13.2 \pm 0.9(44)$ & $<0.001$ \\
\hline \multicolumn{4}{|l|}{ Cows fitted with activity monitors } \\
\hline Duration of activity, $\mathrm{h}$ & - & $13.0 \pm 0.8(98)$ & - \\
\hline Onset of threshold activity to peak activity, $\mathrm{h}$ & - & $5.9 \pm 0.6(98)$ & - \\
\hline Peak activity to ovulation, no. & - & $19.8 \pm 0.7(80)$ & - \\
\hline Onset of threshold activity to ovulation, $\mathrm{h}$ & - & $25.7 \pm 0.4(97)$ & - \\
\hline End of threshold activity to ovulation, $\mathrm{h}$ & - & $13.1 \pm 0.8(80)$ & - \\
\hline
\end{tabular}

${ }^{1}$ Estrus is defined as standing to be mounted and activity represents when the threshold of activity was first achieved.

${ }^{2}$ Results are presented as LSM \pm SEM, with the number of cows in parentheses.

${ }^{3}$ Cow Chips LLC (Manalapan, NJ).

${ }^{4}$ Refers to duration, onset, or end of activity above the threshold.

1.4 to $3.4 \pm 0.8 \mathrm{~h}$ (a negative number indicates that increased physical activity threshold occurred before the first standing event).

The relative proportion of cows fitted with both activity monitors and HW transmitters that ovulated after detection by either standing to be mounted or by reaching the activity threshold is illustrated (Figure $2)$. A tendency $(P=0.06)$ occurred for more activitymonitored cows to ovulate between 20 and $24.9 \mathrm{~h}$ after

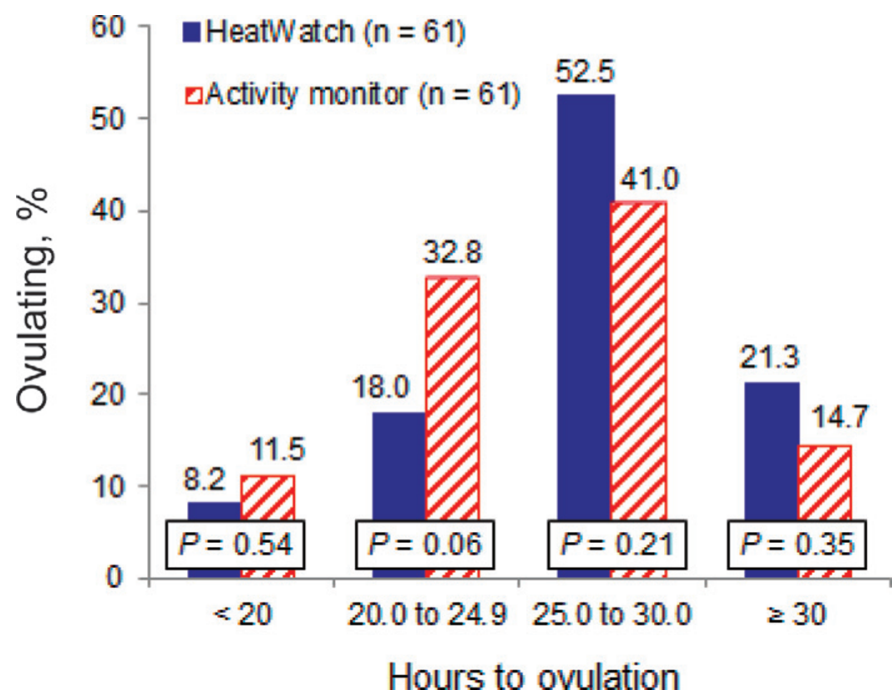

Figure 2. Hours to ovulation after first standing to be mounted or achieved threshold activity in lactating dairy cows fitted with HeatWatch pressure-sensitive, rump-mounted, estrus-detection devices (Cow Chips LLC, Manalapan, NJ) and automated activity accelerometers (Select Detect; Select Sires Inc., Plain City, OH; experiment 1). Color version available in the online PDF. achieving the threshold compared with cows identified in standing estrus. Average intervals to ovulation, however, actually differed $(P<0.05)$ by only $1.5 \mathrm{~h}$ in 59 cows with complete HW and SDet data (Table 2).

Mean interval to ovulation after the end of estrus or end of increased activity was greater $(P<0.001)$ for HW than for SDet, whereas duration of activity was greater $(P<0.001)$ for SDet than HW (Table 2$)$. Peak threshold activity occurred $5.9 \pm 0.6 \mathrm{~h}$ after the onset of achieved threshold activity, and peak activity to ovulation averaged $19.8 \pm 0.7 \mathrm{~h}$ (Table 2).

As duration of threshold activity increased, the interval from onset of activity to ovulation also increased (r $=0.28 ; P=0.013)$. This positive relationship also held for cows identified in standing estrus in which interval to ovulation after first standing event increased as duration of estrus increased $(\mathrm{r}=0.33 ; P=0.031)$.

Relationships between intervals to ovulation after first standing estrus and after achieved activity threshold were correlated ( $\mathrm{r}=0.72$; Figure 3 ). In contrast, the relationship between interval to ovulation after the last standing event or after threshold activity ended was less strong ( $\mathrm{r}=0.34$; Figure 4$)$. Furthermore, the relationship between duration of estrus and duration of threshold activity was less well correlated $(r=0.22$; Figure 5).

Intervals to ovulation after the end of the threshold tended $(P=0.09)$ to be greater in multiparous $(\mathrm{n}=31)$ than primiparous $(\mathrm{n}=49)$ cows, with means of $15.5 \pm$ 1.6 and $11.8 \pm 1.1 \mathrm{~h}$, respectively. Likewise, intervals to ovulation after the start of threshold activity tended $(P=0.10)$ to differ between 63 primiparous $(25.4 \pm$ $0.5 \mathrm{~h})$ and 34 multiparous cows $(27.0 \pm 0.8 \mathrm{~h})$ fitted 


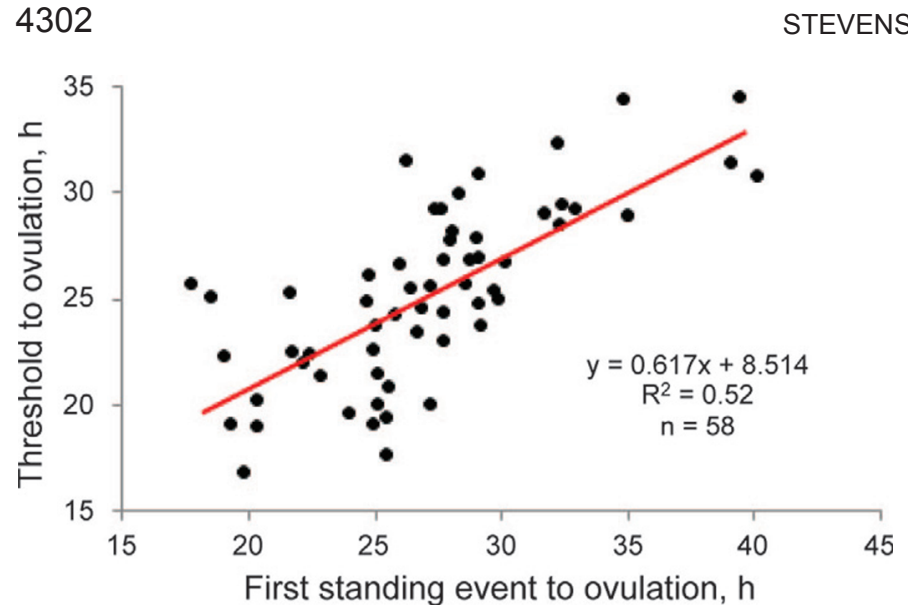

Figure 3. Relationship between interval from first standing to be mounted and achieved threshold activity and time of ovulation in lactating dairy cows fitted with HeatWatch pressure-sensitive, rumpmounted, estrus-detection devices (Cow Chips LLC, Manalapan, NJ) or automated activity accelerometers (Select Detect; Select Sires Inc., Plain City, OH; experiment 1). Color version available in the online PDF.

with activity monitors. Furthermore, intervals to ovulation from peak threshold activity differed $(P=0.05)$ between primiparous $(18.7 \pm 0.9 \mathrm{~h})$ and multiparous cows $(22.2 \pm 1.4 \mathrm{~h})$.

Neither BCS nor $\mathrm{PGF}_{2 \alpha}$ injection (spontaneous vs. induced estrus) affected these ovulation intervals relative to start, peak, or end of threshold activity. Daily milk yield, however, had small effects on time of ovulation from either achieved or peak threshold. Cows producing $>45 \mathrm{~kg}$ of daily milk ovulated from $2.4 \pm 0.6$ to $4.0 \pm 1.1 \mathrm{~h}$ earlier compared with cows producing $\leq 45 \mathrm{~kg}$ of milk. Duration of threshold activity was not affected by parity, BCS, or $\mathrm{PGF}_{2 \alpha}$ injection.

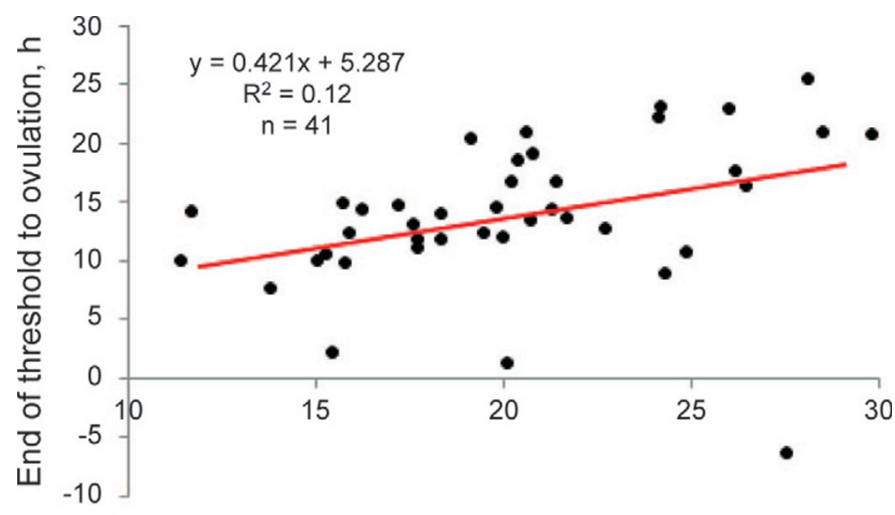

Last standing event to ovulation, $\mathrm{h}$

Figure 4. Relationship between interval from last standing to be mounted and end of threshold activity and time of ovulation in lactating dairy cows fitted with HeatWatch pressure-sensitive, rump-mounted, estrus-detection devices (Cow Chips LLC, Manalapan, NJ) or automated activity accelerometers (Select Detect; Select Sires Inc., Plain City, OH; experiment 1). Color version available in the online PDF.

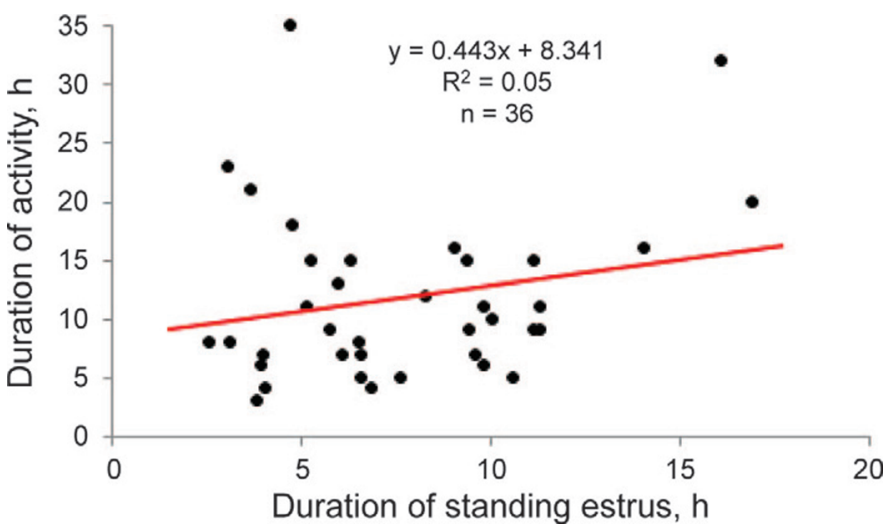

Figure 5. Relationship between duration of standing estrus and threshold activity in lactating dairy cows fitted with HeatWatch pressure-sensitive, rump-mounted, estrus-detection devices (Cow Chips LLC, Manalapan, NJ) or automated activity accelerometers (Select Detect; Select Sires Inc., Plain City, OH; experiment 1). Color version available in the online PDF.

Preovulatory ovarian follicles averaged $16.4 \pm 0.2 \mathrm{~mm}$ in diameter for single-ovulating cows and $13.5 \pm 0.3$ $\mathrm{mm}$ for the second largest follicle in double-ovulating (17.1\%) cows. No relationships were detected between follicle size and other ovulation characteristics.

Conception risk averaged $48.8 \%$ in 43 cows inseminated as part of this study (10 to $14 \mathrm{~h}$ after threshold was achieved). Conception risks in cows for the following intervals after the achieved threshold were 3 of 3 $(100 \%)$ for $<20$ h, 8 of $16(50 \%)$ for 20 to 24.9 h, 6 of $16(37.5 \%)$ for 25 to $29.9 \mathrm{~h}$, and 4 of $8(50 \%)$ for $\geq 30 \mathrm{~h}$.

\section{Experiment 2}

Various reproductive characteristics are summarized for cows fitted with activity monitors versus those receiving timed AI (Table 3). Because of the experimental conditions of initiating AI earlier at 50 DIM in the activity system, days to first AI service were expectedly fewer $(P<0.01)$ for primiparous and multiparous cows inseminated based on the achieved activity threshold compared with cows receiving timed AI. An interaction $(P<0.001)$ between parity and AI system also was detected. Average days to first AI included 7.1\% of the activity monitor cows that received a timed AI between 85 and 91 DIM because they had not yet been inseminated. Some activity-group cows $(9.1 \%)$ were inseminated before 54 DIM, whereas the remaining cows received $\mathrm{PGF}_{2 \alpha}$ to induce estrus after 54 DIM. A scatter plot of DIM at first AI for all cows also illustrates some timed AI cows that were not inseminated as designed (Figure 6), similar to what is observed in almost all herds using a timed AI program.

Conception risk in primiparous cows did not differ between timed AI and activity groups, whereas 


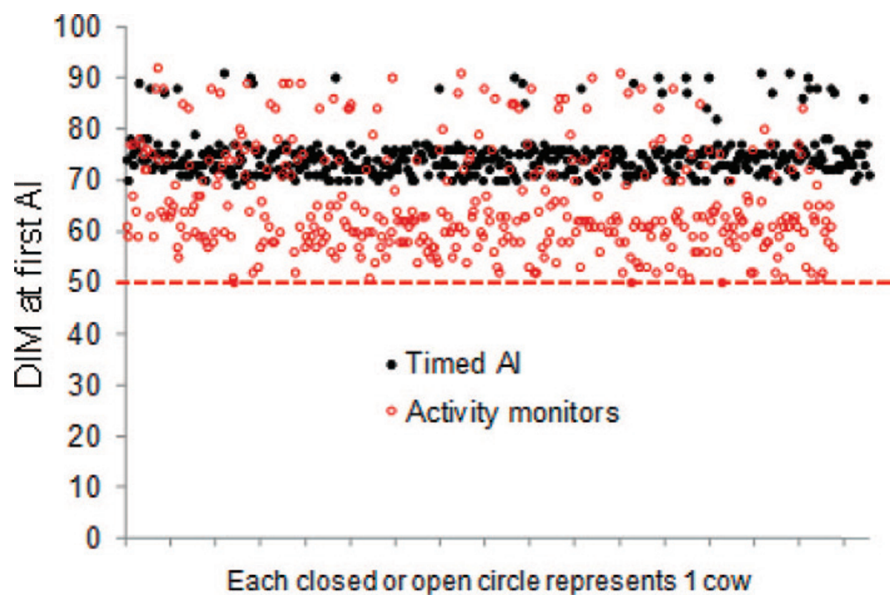

Figure 6. Scatter plot illustrating days to first postpartum AI for cows fitted with automated activity monitors $(\mathrm{n}=394)$ and cows receiving a timed $\mathrm{AI}(\mathrm{n}=413$; experiment 2$)$. Color version available in the online PDF.

in greater milk-producing older cows, conception risk was less $(P<0.001)$ when cows were inseminated after the activity threshold compared with timed AI (Table $3)$. The estrus-detection rate was 1.8 times greater for cows in the activity group compared with those in the timed AI system. The overall conception risk from herd records was numerically less for AI after activity than after timed AI (Table 3).

The proportion of cows pregnant at 150 DIM was 1.3 times greater for activity-group cows than timed-AI cows (Table 3). Kaplan-Meier survival curves indicate that the activity monitor cows became pregnant earlier $(P<0.001)$ in lactation than timed-AI cows $[50 \%$

Table 3. Reproductive characteristics of lactating cows submitted for insemination based on either timed AI or activity monitors in 1 herd (experiment 2)

\begin{tabular}{lcc}
\hline & \multicolumn{2}{c}{ System } \\
\cline { 2 - 3 } Item & $\begin{array}{c}\text { Timed } \\
\text { AI }\end{array}$ & $\begin{array}{l}\text { Activity } \\
\text { monitor }\end{array}$ \\
\hline Cows, no. & 413 & 394 \\
Days at first $\mathrm{AI}^{1}$ & & \\
$\quad$ Primiparous & $76.1 \pm 0.6$ & $64.1 \pm 0.6^{*}$ \\
$\quad$ Multiparous & $74.3 \pm 0.5$ & $67.6 \pm 0.5^{*}$ \\
Conception risk at first AI, ${ }^{2} \%$ & & \\
$\quad$ Primiparous & 38.6 & 36.4 \\
$\quad$ Multiparous & 41.0 & $24.7^{*}$ \\
Overall conception risk, ${ }^{3} \%$ & 44 & 35 \\
Estrus-detection rate, ${ }^{3} \%$ & 42 & 74 \\
Pregnant at 150 DIM, ${ }^{3} \%$ & 52 & 68 \\
\hline I $\%$ & &
\end{tabular}

\footnotetext{
${ }^{1}$ Interaction $(P<0.001)$ between parity and system.

${ }^{2}$ Interaction $(P=0.037)$ between parity and system.

${ }^{3}$ Statistical analyses could not be performed for these traits derived from DHI records (PCDART software; Dairy Records Management Systems, Raleigh, NC).

*Differs $(P \leq 0.05)$ from timed AI within parity.
}

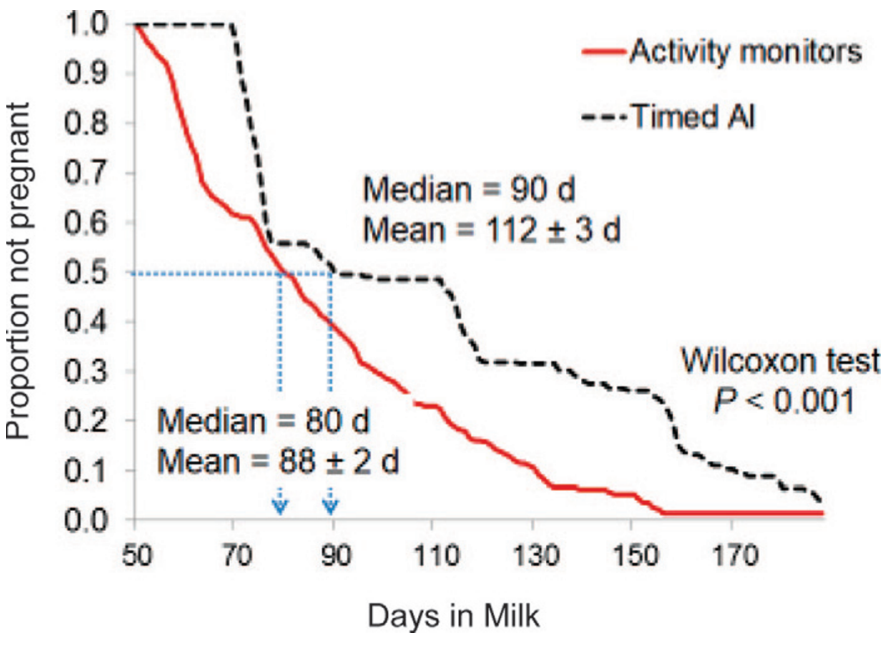

Figure 7. Kaplan-Meier survival curves for proportion of cows not pregnant according to whether cows were enrolled in either a timed AI program through 3 inseminations or inseminated after achieved activity threshold measured by automated activity monitors (experiment 2 ). Color version available in the online PDF.

of the activity-group cows had conceived by 80 DIM compared with $50 \%$ of the timed-AI cows by 90 DIM (Figure 7)]. According to DHI herd records, the annual 21-d pregnancy rate was 25 and $21 \%$ for the activitygroup and timed-AI cows, respectively.

\section{Experiment 3}

Activity Measures. Circadian onset of achieved activity threshold was 0000 to $0559 \mathrm{~h}=32.6 \%, 0600$ to $1159 \mathrm{~h}=21.4 \%, 1200$ to $1759 \mathrm{~h}=18.8 \%$, and 1800 to $2359 \mathrm{~h}=27.1 \%$. Mean duration of activity was 10.2 $\pm 0.1 \mathrm{~h}$, with a median of $10 \mathrm{~h}$, indicating a slightly skewed distribution. The distribution of duration of threshold activity was $19.3 \%$ for $\leq 4 \mathrm{~h}, 20.2 \%$ for 5 to $8 \mathrm{~h}, 45.3 \%$ for 9 to $16 \mathrm{~h}$, and $15.2 \%$ for $\geq 16 \mathrm{~h}$. Farm $(P<0.001)$, season by farm interaction $(P=0.004)$, peak daily milk yield $(P=0.024)$, and season by parity $(P=0.047)$ influenced duration of activity, but DIM $(P=0.17)$ and parity $(P=0.56)$ had no effect. Mean duration of activity on 15 farms ranged from $6.9 \pm 0.8$ to $12.0 \pm 0.3 \mathrm{~h}$. For 1,661 cows with a peak milk yield $<49 \mathrm{~kg}$ per day, the duration of activity averaged $0.6 \pm$ $0.2 \mathrm{~h}$ less $(P=0.024)$ than for 1,714 cows with a peak milk yield $\geq 49 \mathrm{~kg}$ per day. Activity duration during the summer for primiparous cows did not differ from the rest of the year $[9.7 \pm 0.3(\mathrm{n}=800)$ vs. $9.4 \pm 0.3 \mathrm{~h}(\mathrm{n}$ $=628$ ), respectively], whereas duration of activity for multiparous cows was slightly shorter $(P=0.047)$ during the summer than during the rest of the year $[9.1 \pm$ $0.2(\mathrm{n}=1,215)$ vs. $9.7 \pm 0.2 \mathrm{~h}(\mathrm{n}=757)$, respectively].

Peak activity counts were influenced by season $(P=$ $0.015)$, farm $(P<0.001)$, season by farm $(P<0.025)$, 
Table 4. Analysis of variance (PROC GLIMMIX of SAS; SAS Institute Inc., Cary, NC) results for conception risk in a 19-herd study in which cows fitted with automated activity monitors were submitted to AI at random intervals after achieving threshold activity (experiment 3)

\begin{tabular}{lccc}
\hline Source of variation $^{1}$ & df & $F$-value & $P$-value \\
\hline Parity & 1 & 34.28 & $<0.0001$ \\
Service number & 2 & 4.35 & 0.013 \\
Duration of activity & 1 & 9.83 & 0.0017 \\
Peak threshold activity & 1 & 5.23 & 0.022 \\
Interval to AI & 4 & 1.85 & 0.12 \\
Parity $\times$ service number & 2 & 2.67 & 0.069 \\
Parity $\times$ interval to AI & 4 & 2.35 & 0.052 \\
Service number $\times$ duration of activity & 2 & 3.45 & 0.032 \\
Season (farm) & 32 & 2.90 & $<0.0001$ \\
\hline
\end{tabular}

${ }^{1}$ Parity $=$ primiparous versus multiparous; service number $=1,2$, or $3+;$ duration of activity above threshold $=$ $<10$ versus $\geq 10 \mathrm{~h}$; peak threshold activity $=\leq 150$ versus $>150$ counts; interval to AI from achieved threshold $=<4,5$ to 8,9 to 12,13 to 16 , or $>17 \mathrm{~h} ; 2$-way interactions; and season nested within farm.

and parity $(P=0.002)$, but DIM $(P=0.70)$, peak milk $(P=0.96)$, and season by parity $(P=0.30)$ were without effect. Primiparous cows had greater $(P=0.002)$ peak activity than multiparous cows $[175 \pm 3.8(\mathrm{n}=$ $1,428)$ vs. $161 \pm 3.3$ counts $(\mathrm{n}=1,661)]$, respectively.

Conception Risk. Overall conception risk averaged $34.9 \%$. Although duration of threshold activity ranged from 0 to $36 \mathrm{~h}$, conception risk was relatively uniform. Conception risk was $<30 \%$ for activity durations ranging from 0 to $3 \mathrm{~h}(27.2 \% ; \mathrm{n}=635)$, and was never $<30 \%$ thereafter, except for activity durations of $23 \mathrm{~h}(27.3 \%$; $\mathrm{n}=22)$ and $25 \mathrm{~h}(22.2 \% ; \mathrm{n}=18)$. In fact, although the number of AI was small for activity durations $>26 \mathrm{~h}$, the conception risk averaged $42.9 \%(\mathrm{n}=28)$, indicating little evidence that prolonged activity was abnormal or

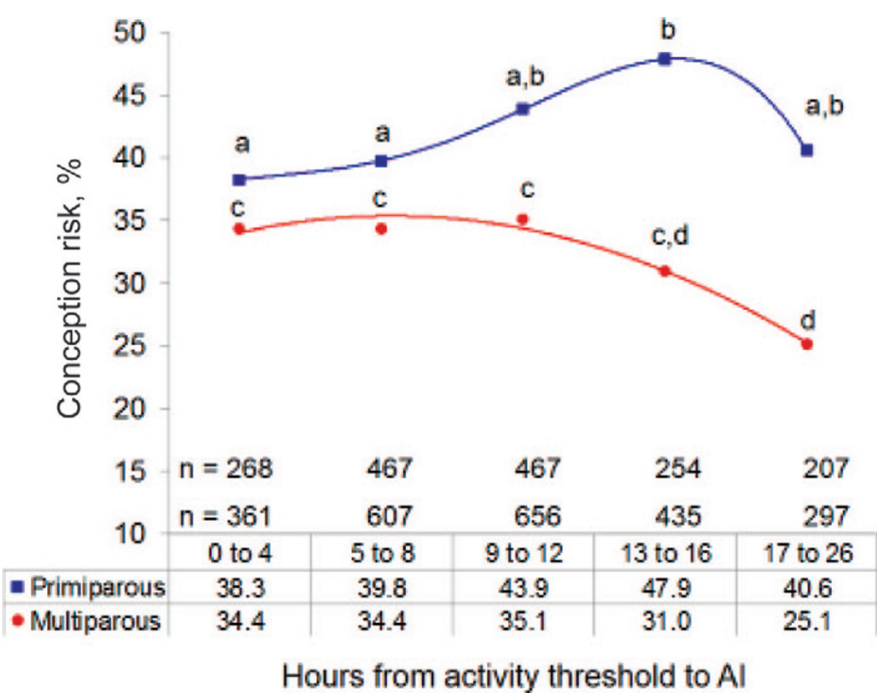

Figure 8. Conception risk of lactating cows in 19 herds in which inseminations were administered randomly at various intervals after achieved activity threshold measured by automated activity monitors (experiment 3). Within parity, data points with different letters (a-d) differ $(P<0.05)$. Color version available in the online PDF. associated with follicular cystic ovarian structures. A total of 195 periods of activity was determined to be $<0.5 \mathrm{~h}$ in duration and initially considered potential artifacts of social activity associated with pen moves and regrouping. Conception risk, however, was only modestly compromised (28.7\%). Because of the relatively large incidence (4.8\% of all activity periods) of these short activity durations, these observations were not excluded from any comparisons of conception risk.

Variance associated with the final binomial analyses of conception risk (Table 4) indicated several significant sources of variation. Of greatest interest was the parity by interval to AI interaction that produced differing fertility responses in primiparous and multiparous cows (Figure 8). Among primiparous cows, a curvilinear relationship was apparent, with maximum conception occurring at $\mathrm{AI}$ intervals of 13 to $16 \mathrm{~h}$ after cows had achieved threshold activity and trended for lesser conception risk for both earlier and later AI intervals. Among multiparous cows, conception risk at intervals $\leq 12 \mathrm{~h}$ was different from those $>16 \mathrm{~h}$, with the 13 to $16 \mathrm{~h}$ interval being intermediate.

Conception risk was influenced by an interaction between service number and duration of activity (Table 4). At first service, conception risk for activity durations $<10$ versus $\geq 10 \mathrm{~h}$ averaged $36.2 \%(\mathrm{n}=704)$ and $40.1 \%$ ( $\mathrm{n}=764)$, respectively. At second service, conception risk was reduced $(P=0.032)$ in cows having shorter activity durations compared with longer activity [33.3\% $(\mathrm{n}=441)$ vs. $45.0 \%(\mathrm{n}=517)$, respectively], whereas at third or greater services, activity duration had no effect on conception risk $[<10 \mathrm{~h}=33.2 \%(\mathrm{n}=706)$ vs. $\geq 10$ $\mathrm{h}=33.8 \%(\mathrm{n}=887)$, respectively].

As expected, conception risk was greater $(P<0.001)$ in primiparous than multiparous cows $[42.1 \%$ ( $\mathrm{n}=$ $1,663)$ vs. $31.9 \%$ ( $\mathrm{n}=2,356)$, respectively]. Furthermore, primiparous cows had greater conception risk at first $(45.5 \% ; \mathrm{n}=650)$ and second $(44.6 \% ; \mathrm{n}=412)$ 
compared with third-or-greater services $(36.2 \% ; \mathrm{n}=$ 601 ), whereas service number had no effect on conception risk in older cows at first $(31.2 \% ; \mathrm{n}=818)$, second $(33.6 \% ; \mathrm{n}=546)$, or third-or-greater services $(30.8 \%$; $\mathrm{n}=992)$.

\section{DISCUSSION}

Increased walking activity associated with estrus led to the development of pedometry as a means of detecting estrus as early as the 1970s (Roelofs et al., 2010). Cows housed in freestalls were approximately 2.75 times more active during estrus than when not in estrus, and relatively little within-cow variation in activity occurred from day to day when cows were not in estrus (Roelofs et al., 2010). Pedometers affixed to the leg or neck-collar-mounted monitors quantified cow movement or the number of steps taken by the cow. Monitoring activity has formed the basis for many pedometer or neck-mounted monitoring systems marketed to the dairy industry because increased activity (e.g., motion, movement, and walking) is a trait correlated with estrus, shown to have increased up to $400 \%$ in 93\% of estrous periods (Kiddy, 1977). Because activity monitors provide 70 to $80 \%$ accuracy of detected estrus (Saint-Dizier and Chastant-Maillard, 2012), activity monitors can be helpful predictors of sexual and other behaviors associated with estrus.

Interval to ovulation detected by $\mathrm{HW}$ in experiment 1 and in an earlier report (Walker et al., 1996) was similar and repeatable between studies. Interval to ovulation after achieved activity threshold in experiment 1 was similar to that for cows in standing estrus, occurring just less than $2 \mathrm{~h}$ earlier, on average (Table 2). Closeness in mean times to ovulation for the activity system used in experiment 1 compared with first standing events validates the effectiveness of this type of technology. The relationships between increased activity and time of ovulation have been investigated with other activity monitors (LópezGatius et al., 2005; Roelofs et al., 2005; Hockey et al., 2010a,b; Yoshioka et al., 2010). In the latter studies, ovulation took place, on average, 29 to $33 \mathrm{~h}$ after the onset of increased activity and 17 to $19 \mathrm{~h}$ after the end of increased activity in lactating Holstein cows. One study estimated timing of ovulation by applying concurrently to each cow a pressure-sensitive, rumpmounted radiotelemetric device and a foreleg-attached pedometer, which measured steps, to determine the onset of estrus (Yoshioka et al., 2010). Ovaries in 20 cows were scanned transrectally every $2.5 \mathrm{~h}$ beginning $20 \mathrm{~h}$ after first standing estrus until the ovulatory follicle disappeared, revealing duration of activity of 15.8 $\pm 0.9 \mathrm{~h}$, ovulation after start of activity of $30.2 \pm 0.6$ $\mathrm{h}$, and ovulation after end of activity of $15.3 \pm 0.9 \mathrm{~h}$. Their findings are closely similar to our observations in 98 cows (Table 2).

Another report (Hockey et al., 2010a), using neckmounted activity monitors, reported mean (mean \pm SD) times from onset and from end of increased activity to ovulation of $33.4 \pm 12.4$ and $17.3 \pm 12.8 \mathrm{~h}$, respectively, in 94 ovulatory periods (prediction of ovulation was less precisely determined by ovarian exams made by using transrectal ultrasound at 12-h intervals). Proportions of cows that ovulated after the onset of increased activity were $50 \%$ at 30 to $38 \mathrm{~h}, 76.6 \%$ at 24 to $40 \mathrm{~h}$, $85.1 \%$ at 18 to $42 \mathrm{~h}$, and $90.4 \%$ at 19 to $51 \mathrm{~h}$. Another study (Roelofs et al., 2005), using front leg-mounted pedometers, reported ovulation occurring $29.3 \pm 3.9$ $\mathrm{h}$ after onset of increased number of steps (22 to 39 $\mathrm{h}$ ) and $19.4 \pm 4.4 \mathrm{~h}$ after the end of increased number of steps (12 to $35 \mathrm{~h}$ ). The reported intervals were not influenced by the number of cows in estrus at the same time or by parity.

In previous studies (Roelofs et al., 2005; Hockey et al., 2010a; Yoshioka et al., 2010) and in experiment 1, predicted time of ovulation was in reasonable agreement with the study of Walker et al. (1996), in which ovulation occurred at $27.6 \pm 5.4 \mathrm{~h}$ (mean $\pm \mathrm{SD}$ ) after the onset of estrus. In the latter study, $78 \%$ of cows ovulated before $40 \mathrm{~h}$ after onset of estrus, and a large proportion (73\%) that failed to ovulate before $40 \mathrm{~h}$ were those induced to estrus with $\mathrm{PGF}_{2 \alpha}$. In experiment 1 , $21.3 \%$ of cows detected in estrus and $14.7 \%$ of activitydetected cows ovulated more than $30 \mathrm{~h}$ after detection of estrus or achieved the activity threshold (Figure 2), respectively, indicating that a small population of cows in both studies ovulated later than expected and may contribute to reproductive culling because of failure to conceive. Finally, from the literature cited, it seems likely that increased activity is well correlated with the onset of standing estrus in studies where simultaneous measures were made.

Acceptance and use of automated activity monitors as estrus-detection aids have grown. A National Animal Health Monitoring System survey (NAHMS, 2007) of US dairy operations in 2006 reported visual detection of estrus as the most common approach (93\%), whereas only $7 \%$ of operations were using some type of electronic technology. Since the National Animal Health Monitoring System survey was completed, several milking machine companies and other dairy suppliers (including the 6 major AI companies in the United States) have begun marketing activity monitor technology for use in dairy operations. Nine marketed activity systems currently have the ability to interface with 1 of the DHIA record-processing centers (PCDART; Dairy Records Management Systems). 
By 2010, one of the best-selling activity systems globally, with approximately 1 million estrus-detection monitors sold, demonstrated that dairy farmers were willing to invest in technologies that provided a practical solution to detection of estrus. A survey (Michaelis et al., 2013) of 219 dairy farmers who had used the same automated activity system revealed almost unanimous satisfaction (94.1\%). More than $93 \%$ agreed that estrus-detection rates had increased, $92.3 \%$ believed reproduction had become more easily managed, and 94.5\% indicated they would install the system again.

Activity-monitoring systems have limitations. Several studies have determined the accuracy and efficiency of activity monitors in identifying estrus. In one study (Aungier et. al., 2012), physical activity of 89 spring-calving cows on pasture were monitored by activity monitors. Based on twice-weekly samples of progesterone, the activity monitors identified $72 \%$ of the preovulatory follicular phases (69 conceptions resulted from $145 \mathrm{AI}$ ). One-third of the activity clusters were associated with elevated progesterone (i.e., false positives).

In another study (Valenza et al., 2012), 112 lactating cows housed in freestalls were treated with $\mathrm{GnRH}$ and $\mathrm{PGF}_{2 \alpha} 7 \mathrm{~d}$ later. For cows to be enrolled in the study, 3 criteria must have been met at the time of $\mathrm{PGF}_{2 \alpha}$ treatment: (1) a visible corpus luteum, (2) a follicle $>10$ $\mathrm{mm}$ in diameter, and (3) subsequent luteolysis by 48 $\mathrm{h}$ after $\mathrm{PGF}_{2 \alpha}$ treatment. Cows were fitted with activity monitors and heat-mount patches to detect estrus. Activity monitors identified only $71 \%$ of the cows in estrus during $7 \mathrm{~d}$ after $\mathrm{PGF}_{2 \alpha}$ injection, of which $95 \%$ ovulated. Of the $29 \%$ of cows not detected by the activity monitor, $35 \%$ ovulated.

A third report (Kamphuis et al., 2012) compared 2 types of commercially available collar-mounted activity monitors with visual observation of estrus in pasturegrazed cows during a 37-d AI season. Milk progesterone and AI records served to identify positive and negative estrus dates. Visual assessment and both activity systems excelled in identifying cows not in estrus (specificity), whereas both activity systems were less effective than visual observation in identifying true estrus (sensitivity) and correctly diagnosing estrus in cows that were truly in estrus (positive predictive value).

A more comprehensive review of the efficiency, specificity, and accuracy of estrus detection by activity monitors attached to the leg or neck of dairy cows was reported for 7 different studies of more than 4,700 dairy cows (Saint-Dizier and Chastant-Maillard, 2012). Efficiency was generally in excess of $80 \%$, and specificity ranged from 90 to $100 \%$, but their accuracy varied considerably, depending on the devices and the algorithm used by the software. Although no clear difference in sensitivity, specificity, and accuracy of neck-mounted monitors was detected in 2 dairy herds that differed markedly in cow environment and calving system (Hockey et al., 2010a), their performance was likely affected by environmental conditions, housing type, and other management variables (Saint-Dizier and Chastant-Maillard, 2012). Whether these variables alter the interval to ovulation after onset of achieved threshold activities is not known.

Our within-herd comparison of the activity system versus a timed-AI program through 3 AI services in experiment 2 demonstrated earlier establishment of pregnancy for cows submitted to AI based on activity, despite better conception risk at the first timed-AI services in multiparous cows (Table 3 ). The difference in days to first AI service is an artifact of having 2 different voluntary waiting periods, which was necessitated by incorporating both systems into the same herd. Part of the difference in first-service outcomes probably resulted from inseminating cows earlier postpartum, but the difference in voluntary waiting period may not explain why pregnancy per timed AI in multiparous cows was greater than that in their herd mates inseminated based on activity. Delaying first services in Holstein cows in Germany receiving timed AI at first service, but not amount of milk production, had a major positive influence on conception risk after timed AI (Tenhagen et al., 2003).

Although not assessed statistically, overall conception risk seemed to be less at all 3 services for activitygroup cows, but the estrus-detection rate seemed to be greater than that for timed-AI cows. Also not assessed, the interinsemination interval must have been reduced in activity-group cows compared with timed-AI cows because of (1) improved estrus-detection rate and subsequent AI submission rate in activity-monitored cows (Table 3) and (2) more cows becoming pregnant earlier postpartum (Figure 7).

In 3 commercial dairy herds, reproductive performance with management programs based on automated activity monitoring or a timed-AI program were compared (Neves et al., 2012). Similar to experiment 2, half of the cows in each herd were enrolled in a timedAI program, whereas the remaining half was submitted to AI based on automated activity monitors. A herd by breeding program interaction was detected such that the automated activity monitoring system and timed AI-based program produced different outcomes among herds. Median days to first AI service and to pregnancy did not differ between programs in 2 herds, but were fewer for activity cows in the third herd in which 6 -mo periods for 1,985 cows were examined. Results were partly confounded by the fact that 19 to $32 \%$ of all inseminations in both systems were made after 
visual estrus detection (not according to the timed-AI or activity system). Considering only 6 -mo periods for 924 cows, however, in which inseminations were made only according to the assigned management program, an interaction between herd and breeding program was detected. Time to pregnancy differed in 2 of the 3 herds in which cows inseminated based on activity monitoring became pregnant sooner than timed-AI cows. Furthermore, individual conception risk at each AI did not differ between programs (31\% for activity and 30\% for timed AI).

Appropriate timing of AI to maximize conception risk for cows submitted to AI service based on automated activity monitors is critical. In experiment 3 , with more than 4,000 AI services in 19 herds, results may indicate a slight difference in timing of AI between primiparous and multiparous cows (Figure 8). Clearly, inseminations made after $16 \mathrm{~h}$ in all cows reduced conception risk. Based on timing of ovulation results in experiment 1, AI made 13 to $16 \mathrm{~h}$ after the achieved threshold matched the best conception risk in primiparous cows of experiment 3. Given the need for approximately 6 to $10 \mathrm{~h}$ for sperm transport after AI (Saacke et al., 2000), primiparous cows inseminated at 13 to $16 \mathrm{~h}$ should ovulate, on average, 9 to $12 \mathrm{~h}$ later or approximately 13 $\mathrm{h}$ after the end of threshold activity (Table 2). Saacke et al. (2000) further indicated that timing of AI should allow for an adequate number of sperm to be found in the oviduct near the time of ovulation, resulting in increased accessory sperm trapped in the zona pellucida. Accessory sperm are thought to represent the number of sperm competing for fertilization and are associated with greater fertilization rates (Saacke et al., 2000). Timing of AI is a compromise between poorer fertilization rates and greater embryo quality when cows are inseminated close to the onset of estrus versus greater fertilization rates and poorer embryo quality when cows are inseminated closer to the time of ovulation (Saacke et al., 2000).

This timing of AI approximately 13 to $16 \mathrm{~h}$ after onset of threshold activity is consistent with the a.m.-p.m. rule and the foundational results of Trimberger (1948). Ovulation times for primiparous and multiparous cows did not differ in experiment 1, using the same activity system applied in the 19-herd study (experiment 3), but intervals to ovulation from start, peak, and end of threshold activity were 1.6 to $3.7 \mathrm{~h}$ greater in multiparous than in primiparous cows. Although the average interval to ovulation did not differ, these slightly greater intervals relative to threshold in older cows somewhat disagree with the conception risk information derived from the 19 herds studied. It seems that conception risk peaks in primiparous cows slightly later than in older cows (Figure 8).
One report attempted to link timing of ovulation with actual AI service times (Hockey et al., 2010b). Based on only 202 estimated times of ovulation in 1 herd (transrectal ultrasonography of ovaries at 0,12 , 24 , and $36 \mathrm{~h}$ after $\mathrm{AI}$ ), the greatest conception risk (51\%) was observed for AI from 0 to $16 \mathrm{~h}$ before ovulation (31.2\% of all $\mathrm{AI})$. In contrast, conception risk (29\%) was less for AI from 16 to $32 \mathrm{~h}$ before ovulation, when most of the AI occurred (53.2\%).

\section{CONCLUSIONS}

Automated activity monitors used in this study (Select Detect) closely identify the onset of estrus compared with standing-to-be-mounted activity identified by pressure-sensitive, rump-mounted transmitters (HeatWatch). Average time to ovulation relative to onset of estrus or activity threshold differed by less than $2 \mathrm{~h}$; furthermore, with the activity accelerometer system used, consistency of ovulation time relative to both onset and end of activity were predictable. A within-herd comparison provided evidence that conception risk resulting from AI services based on automated activity monitors was less that than that achieved by timed AI, but more cows became pregnant earlier in lactation (faster rate of achieving more pregnancies per unit of time). Inferred from this study, because of seemingly greater estrus-detection rates and earlier establishment of pregnancy, rate of pregnancy establishment was greater when activity systems were applied because interinsemination intervals were reduced. Our results are consistent with similar studies based on observed mounting activity in which maximal conception risks were obtained when AI intervals were approximately 12 $\mathrm{h}$ after detected activity threshold, with shorter intervals less compromising to conception risk than greater intervals in both younger and older cows. Peak conception risk for younger cows occurred between 13 and 16 $\mathrm{h}$ after achieved threshold. Activity monitors used in these experiments effectively predicted ovulation and best time to AI to maximize conception risk.

\section{ACKNOWLEDGMENTS}

The first author acknowledges Select Sires Inc. (Plain City, $\mathrm{OH}$ ) for providing the Select Detect advanced estrus detection technology system (Dairymaster, Causeway, Co. Kerry, Ireland) hardware, software, and funding for the ovulation study. All authors express appreciation to Select Sires employees and AI technicians for their involvement in data collection for experiments 2 and 3 as well as the 20 dairy herd owners and operators who participated in those studies. 


\section{REFERENCES}

Aungier, S. P. M., J. F. Roche, M. Sheehy, and M. A. Crowe. 2012. Effects of management and health on the use of activity monitoring for estrus detection in dairy cows. J. Dairy Sci. 95:2452-2466.

DRMS (Dairy Record Management Systems). 2013. DHI Glossary Fact Sheet - 8/13. Accessed Mar. 27, 2014. http://www.drms.org/ dhia.aspx?node_id=Dflt7.

Ferguson, J. D., D. T. Galligan, and N. Thomsen. 1994. Principal descriptors of body condition score in Holstein cows. J. Dairy Sci. 77:2695-2703.

Firk, R., E. Stamer, W. Junge, and J. Krieter. 2002. Automation of oestrus detection in dairy cows: A review. Livest. Prod. Sci. $75: 219-232$.

Giordano, J. O., P. M. Fricke, M. C. Wiltbank, and V. E. Cabrera 2011. An economic decision-making support system for selection of reproductive management programs on dairy farms. J. Dairy Sci. 94:6216-6232.

Hockey, C. D., J. M. Morton, S. T. Norman, and M. R. McGowan 2010a. Evaluation of a neck mounted 2-hourly activity meter system for detecting cows about to ovulate in two paddock-based Australian dairy herds. Reprod. Domest. Anim. 45:e107-e117.

Hockey, C. D., J. M. Morton, S. T. Norman, and M. R. McGowan. 2010b. Improved prediction of ovulation time may increase pregnancy rates to artificial insemination in lactating dairy cows. Reprod. Domest. Anim. 45:e239-e248.

Kamphuis, C., B. DelaRue, C. R. Burke, and J. Jago. 2012. Field evaluation of 2 collar-mounted activity meters for detecting cows in estrus on a large pasture-grazed dairy farm. J. Dairy Sci. 95:3045-3056

Kiddy, C. A. 1977. Variation in physical activity as an indicator of estrus in dairy cows. J. Dairy Sci. 60:235-243.

Lewis, G. S., and S. K. Newman. 1984. Changes throughout estrous cycles of variables that might indicate estrus in dairy cows. J. Dairy Sci. 67:146-152.

López-Gatius, F., P. Santolaria, I. Mundet, and J. L. Yániz. 2005. Walking activity at estrus and subsequent fertility in dairy cows. Theriogenology 63:1419-1429.

Michaelis, I., E. Hasenpusch, and W. Heuwieser. 2013. Estrus detection in dairy cattle: Changes after the introduction of an automated activity monitoring system. Tierarztl. Prax. Ausg. G Grosstiere Nutztiere 41:159-165.

NAHMS (National Animal Health Monitoring System). 2007. Reproduction practices on U.S. dairy operations, 2007. APHIS Info Sheet (2009). Accessed Apr. 29, 2014. http://usdasearch.usda.gov/ search utf $8=\% 3 \mathrm{~F} \&$ affiliate $=$ usda-aphis\&query $=$ Reproductive + practices\&commit $=$ Search .

Neves, R. C., K. E. Leslie, J. S. Walton, and S. J. LeBlanc. 2012. Reproductive performance with an automated activity monitoring system versus a synchronized breeding program. J. Dairy Sci. 95:5683-5693.
NRC. 2001. Nutrient Requirements of Dairy Cattle. 7th rev. ed. Natl. Acad. Sci., Washington, DC.

Roelofs, J., F. López-Gatius, R. H. F. Hunter, F. J. C. M. van Eerdenburg, and C. Hanzen. 2010. When is a cow in estrus? Clinical and practical aspects. Theriogenology 74:327-344.

Roelofs, J. B., F. J. van Eerdenburg, N. M. Soede, and B. Kemp. 2005. Pedometer readings for estrous detection and as predictor for time of ovulation in dairy cattle. Theriogenology 64:1690-1703.

Roth, H. 1987. Automatisches Erkennen des Konzeptionsoptimums bei Milchkühen mit Hilfe rechnergestützter Systeme zur Herdenüberwachung. Landbauforschung Völkenrode, Sonderheft 83. Bundesforschungsanstalt für Landwirtschaft, Braunschweig-Völkenrode, Germany.

Saacke, R. G., J. C. Dalton, S. Nadir, R. L. Nebel, and J. H. Bame. 2000. Relationship of seminal traits and insemination time to fertilization rate and embryo quality. Anim. Reprod. Sci. 60-61:663677.

Saint-Dizier, M., and S. Chastant-Maillard. 2012. Towards an automated detection of oestrus in dairy cattle. Reprod. Domest. Anim. 47:1056-1061.

Stevenson, J. S., S. L. Pulley, and H. I. Mellieon Jr. 2012. Prostaglandin $\mathrm{F}_{2 \alpha}$ and gonadotropin-releasing hormone $\mathrm{GnRH}$ administration improve progesterone status, luteal number, and proportion of ovular and anovular dairy cows with corpora lutea before a timed AI program. J. Dairy Sci. 95:1831-1844.

Tenhagen, B. A., C. Vogel, M. Drillich, G. Thiele, and W. Heuwieser. 2003. Influence of stage of lactation and milk production on conception rates after timed artificial insemination following Ovsynch. Theriogenology 60:1527-1537.

Trimberger, G. W. 1948. Breeding efficiency in dairy cattle from artificial insemination at various intervals before and after ovulation. Univ. Nebraska Ag. Exp. Sta. Res. Bull. 153. University of Nebraska, College of Agriculture, Agricultural Experiment Station, Lincoln.

Vailes, L. D., and J. H. Britt. 1990. Influence of footing surface on mounting and other sexual behaviors of estrual Holstein cows. J. Anim. Sci. 68:2333-2339.

Valenza, A., J. O. Giordano, G. Lopes Jr., L. Vincent, M. C. Amundson, and P. M. Fricke. 2012. Assessment of an accelerometer system for detection of estrus and treatment with gonadotropin-releasing hormone at the time of inseminate in lactating dairy cows. J. Dairy Sci. 95:7115-7127.

Walker, W. L., R. L. Nebel, and M. L. McGilliard. 1996. Time of ovulation relative to mounting activity in dairy cattle. J. Dairy Sci. 79:1555-1561.

Yoshioka, H., M. Ito, and Y. Tanimoto. 2010. Effectiveness of real-time radiotelemetric pedometer for estrus detection and insemination in Japanese Black cows. J. Reprod. Dev. 56:351-355. 